Mittlere Oerter der Vergleichsterne fur den betreffenden Jahresanfang.

\begin{tabular}{|c|c|c|c|}
\hline$\bullet$ & $\alpha$ & $\delta$ & Autorität \\
\hline $\mathbf{I}$ & $4^{\mathrm{h}} 32^{\mathrm{m}} 3^{\mathrm{s}} \cdot 6 \mathrm{I}$ & $+12^{\circ} 17^{\prime} 31^{\prime \prime} 9$ & c Tauri. Pulkowa Nr. 700 \\
\hline 2 & 435 I I & +1048 & BD. $+10: 608$ \\
\hline 3 & $43^{1} 32$ & +949 & BD. $+9: 6$ I 6 \\
\hline 4 & 44115 & -440 & BD. $-4^{\circ}: 94^{\circ}$ \\
\hline 5 & 43546.21 & - 65730.7 & Schj. I 497 \\
\hline 6 & $4 \quad 40 \quad 42.00$ & $\begin{array}{llll}-711 & 1.6\end{array}$ & Schj. I 53 I - 32 \\
\hline
\end{tabular}

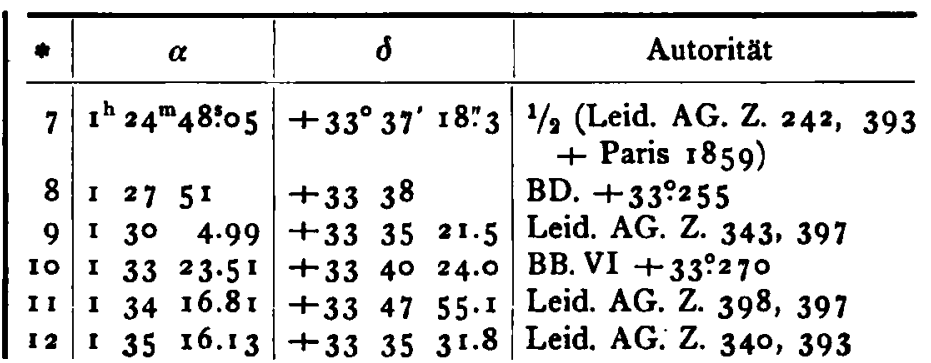

Bemerkungen. Instrument von $244 \mathrm{~mm}$ Oeffnung, Filarmikrometer. Comet Wolf $189 \mathrm{II}$ und, seit dem 20. Januar, Comet Holmes wurden mit hellen Fäden beobachtet. Am 25. u. 26. Jan. hat der Comet Holmes an Intensităt sehr abgenommen. Mondschein. Die Beobachter waren: F. Trocki (T) und M. Gratschew (G), Assistenten der Sternwarte.

Kasan 1893 Febr. 10.

D. Dubiago.

Beobachtungen des Cometen 1892 III (Holmes)

am 182 . Refractor der Kais. Universitätssternwarte in Strassburg.

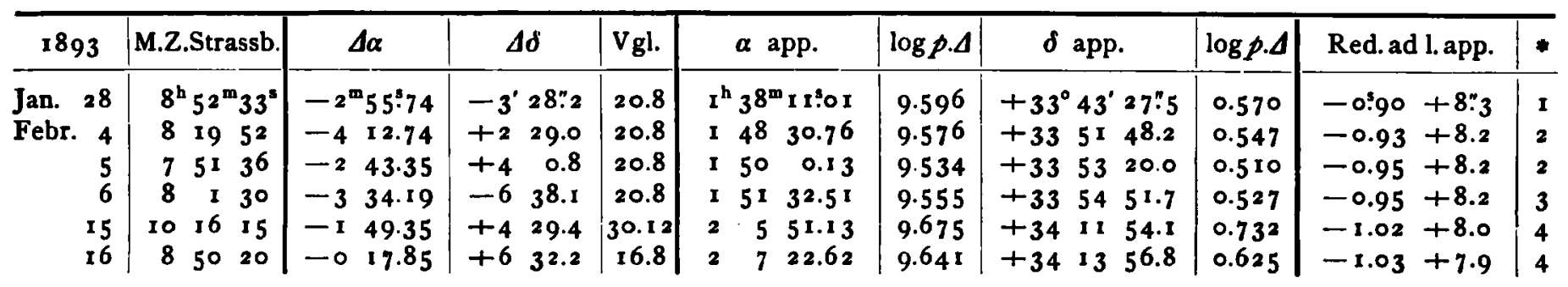

Mittlere Oerter der Vergleichsterne für 1893.0.

\begin{tabular}{|c|c|c|c|}
\hline * & $\alpha$ & $\delta$ & Autorität \\
\hline $\begin{array}{l}\mathbf{I} \\
2\end{array}$ & $\begin{array}{l}1^{\mathrm{b}} 41^{\mathrm{m}} 7^{3} \cdot 65 \\
\text { I } 5^{2} 44 \cdot 43\end{array}$ & $\begin{array}{l}+33^{\circ} 46^{\circ} 47^{\prime \prime} .4 \\
+334911.0\end{array}$ & $\begin{array}{l}\text { Leid AG. Z. } 393,397 \\
\text { Leid. AG. Z. } 393,396\end{array}$ \\
\hline
\end{tabular}

\begin{tabular}{|c|c|c|c|}
\hline$*$ & $\alpha$ & $\delta$ & Autorität \\
\hline 3 & $I^{h} 55^{m} \quad 7^{5}: 65$ & $+34^{\circ} \times 21.6$ & Leid. AG. Z. 325,257 \\
\hline 4 & 2741.50 & $7 \quad 16.7$ & Leid. AG. Z. 239,333 \\
\hline
\end{tabular}

Bemerkungen. Jan. 28. Comet ein blasser Nebel, $1 \frac{1}{2^{\prime}}$ gross, ohne
Verdichtung; nur zuweilen leuchtet ein Kern $\mathbf{I}^{\mathrm{m}}$ auf. Wegen hellen Mondscheins und Nahe eines Sterns 10:5 schwierig zu beobachten. Beobachtung unsicher.

Febr. 4. Comet ein ziemlich heller Nebel von 3' Ausdehnung im Pos.-W. $70^{\circ}$; in dieser Richtung setzt sich der Nebel noch wenigstens $5^{\circ}$ als schwacher Schweif fort; ganz im vorangehenden Theile des Nebels befindet sich eine gut hervortretende Verdichtung und ein hin und wieder aufleuchtender Kern $13^{\mathrm{m}}$.

Febr. 5. Obwohl die Luft durchsichtiger als gestern ist, erscheint der Comet doch schwächer. Sonst keine

Aenderung. Beobachtung ziemlich schwierig; es stören zwei nahe Sterne $1 \mathbf{I}^{\mathrm{m}}$.

Febr. 6. Der Kern tritt heute besser hervor, da keine Sterne stören.

Febr. I5. Comet in Stratus-Gewölk immer nur für kurze Zeit mühsam zu erkennen; Beobachtung daher unsicher. Comet ein runder Nebel von 2' Ausdehnung mit hellerer Mitte.

Febr. 16. Aussehen wie Febr. 15; an der nachfolgenden Seite findet ein ganz allmähliches Erblassen der Helligkeit des Nebels statt.

Strassburg 1893 Febr. 21 .

H. Kobold.

\title{
Beobachtung des Cometen 1892 III (Holmes).
}

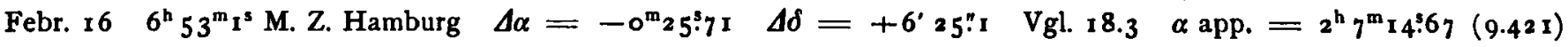
$\delta$ app. $=+34^{\circ} 13^{\prime} 49^{\prime \prime} 4$ (0.548). Corr. der Ephemeride Schulhof (A. N. $\left.3^{1} 40\right)$ : +15.2, $-8^{\prime \prime}$.

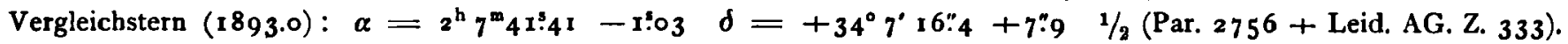

Bei nebliger Luft Comet verhältnissmässig gut zu beobachten, erscheint.etwas heller als Febr. 11 . Die schwache Verdichtung tritt deutlich hervor.

Hamburg, Sternwarte, 1893 Febr. 2 I.

R. Schorr. 